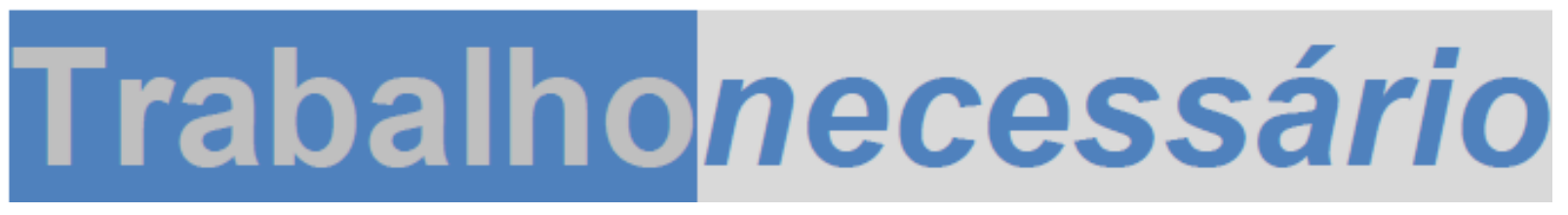

Issn: 1808 - 799X

ano 11 , no $16-2013$

\title{
PEDAGOGIA POLÍTICA RENOVADA E A POLÍTICA PÚBLICA DE TRABALHO, QUALIFICAÇÃO E GERAÇÃO DE RENDA: A INSTITUCIONALIDADE DA CONFORMAÇÃO DAS CLASSES SUBALTERNAS ${ }^{1}$
}

\author{
Bruno de Oliveira Figueiredo²
}

\begin{abstract}
Resumo: O objetivo desse artigo é apresentar uma compreensão das dimensões e dos aspectos que inscrevem a política pública de trabalho, qualificação e geração de emprego e renda, no Brasil, como mecanismo estratégico da atual pedagogia política, analisada a partir da reconfiguração do projeto socialdemocrata ou dos partidários da Terceira Via. Sintetizam-se as linhas gerais desse projeto de alcance mundial, para verificar a correspondência com os pressupostos, princípios e diretrizes da atual configuração da articulação entre a política pública de trabalho e renda e a política de formação/qualificação profissional. A hegemonia do projeto neoliberal mediatizado pela Terceira Via, desde meados dos anos 1990, definiu essa reconfiguração. Para alcançar esse objetivo, analisou-se o Plano Nacional de Formação Profissional (PLANFOR) e seu substituto, o Plano Nacional de Qualificação (PNQ), como principais mecanismos daquela política pública. Identificaram-se os aspectos da atual pedagogia política nos documentos do PLANFOR e do PNQ, evidenciando serem esses Planos mecanismos estratégicos de mediação do conflito de classes e conformação da sociabilidade burguesa necessária ao atual estágio de desenvolvimento do capitalismo monopolista.
\end{abstract}

Palavras-chave: estado, hegemonia, política educacional.

\footnotetext{
${ }^{1}$ Esse artigo foi publicado originalmente nos Anais do VII Colóquio Internacional de Marx e Engels (UNICAMP), constituindo-se em uma versão revisada e ampliada.

${ }^{2}$ Mestre em Educação pela UFRRJ. Professor Temporário do Departamento de Administração e Turismo (DAT), do Instituto Multidisciplinar (IM), da UFRRJ e da Faculdade Internacional Signorelli. Membro do Grupo de Pesquisas sobre Trabalho Política e Sociedade (GTPS), da UFRRJ. E-mail: mbrunosaar@yahoo.com.br
}

TrabalhoNecessário - www.uff.br/trabalhonecessario; Ano 11, № 16/2013. 


\title{
Trabalhonecessário
}

Issn: 1808 - 799X

ano 11, no $16-2013$

\begin{abstract}
The objective of this paper is to submit an understanding of the dimensions and aspects that insert public policies of work, qualifications, and of employment and income generation in Brazil, as strategic mechanisms of current political pedagogy, which are analyzed from the reconfiguration of both the social democratic project and the supporters of the Third Way. A synthesis of the outline of this worldwide project was made in order to verify the correspondence to the assumptions, principles and guidelines of the current configuration of the relationship between public policy of work and income, and the policy of training / qualification. The hegemony of the neoliberal project mediated by the Third Way, since the mid 1990's, defined such reconfiguration. The stated objective was pursued through the analysis of both the National Plan of Professional Education [PLANFOR] and its surrogate National Plan of Qualification [PNQ], deemed as the main mechanisms of those public policies. Features of the current political pedagogy were identified in both PLANFOR and PNQ policy documents which evidenced these Plans to be strategic mechanisms for mediation of class conflict and conformation of bourgeois sociability necessary to the present stage of development of monopoly capitalism.
\end{abstract}

KeYwoRDS: State. Hegemony. Educational Policy. 


\section{Trabalhonecessário}

Issn: 1808 - 799X

ano 11, no $16-2013$

\section{Introdução}

Nossa análise tem como referência a atual configuração da luta de classes que vem se modificando a partir da crise estrutural evidenciada no final dos anos 1960 e início dos anos 1970. Em função dessa crise estendida até dias de hoje, a configuração da luta de classes se expressa nas mudanças estruturais e superestruturais, materializadas no reordenamento da esfera produtiva e do papel do Estado (AlVES, 2005; ANTUNES, 2005). Essas mudanças têm como objetivo restabelecer o equilíbrio entre estrutura e superestrutura, para a formação de um novo bloco histórico, ou seja, para a manutenção da hegemonia da concepção de mundo burguês e de seu projeto de sociabilidade (SouZA, 2003).

Como resposta a crise estrutural da ordem capitalista de produção e reprodução social da vida material, desencadeia-se amplo processo de reestruturação produtiva e de recomposição dos mecanismos de mediação do conflito de classe para garantir a retomada das bases de acumulação de capital. Esse processo é caracterizado por intensa inserção de ciência e tecnologia na produção, que provoca diminuição substancial do trabalho vivo e condiciona cada vez mais a capacidade do sistema produtivo em absorver a força de trabalho disponível, configurando o desemprego estrutural e os decorrentes problemas sociopolíticos e econômicos da atualidade (SouZA, 2003).

No campo superestrutural, estas mudanças encontram respaldo em uma nova dinâmica de regulação social onde se ampliam os mecanismos de participação da sociedade civil no controle social das decisões estatais como estratégia de mediação do conflito entre as classes sociais.

A nova regularidade do sistema e a manutenção da hegemonia da classe fundamental exigem do Estado capitalista o desenvolvimento de uma pedagogia 


\section{Trabalhonecessário}

Issn: 1808 - 799X

ano 11, no $16-2013$

política ${ }^{3}$ para a construção do consenso em torno da sociabilidade burguesa no atual estágio do capitalismo monopolista. Como expressão desse desenvolvimento, a reconfiguração do projeto socialdemocrata materializa um projeto de alcance mundial, apresentando como uma suposta alternativa ao projeto neoliberal, uma Terceira Via. Nesse contexto, o Estado brasileiro promove ampla reforma do sistema educacional para adequá-lo às novas demandas do capital.

A reforma do sistema educacional brasileiro se desenvolve com base no recrudescimento da Teoria do Capital Humano, expressa no conceito de empregabilidade. Assim, a educação básica e a educação profissional são acionadas como estratégia privilegiada de formação de trabalhadores de novo tipo. Nesse sentido, a formação/qualificação profissional passa a ser proclamada como fator de geração de emprego e renda, impondo novas bases para a compreensão da relação entre trabalho e educação, conforme materializada no Plano Nacional de Formação Profissional (PLANFOR) ${ }^{4}$ e em seu substituto Plano Nacional de Qualificação (PNQ).

Como objetivo desse artigo, procuramos compreender a influência do projeto neoliberal mediatizado pela Terceira Via na constituição da engenharia institucional da política pública de trabalho, qualificação e geração de renda no Brasil. Assim, primeiramente, procuramos sintetizar as linhas gerais do projeto

\footnotetext{
${ }^{3}$ Nossa compreensão de pedagogia política tem referência na obra de Gramsci (1989). Nessa obra, Gramsci (1989) evidencia o fenômeno da ocidentalização, com a complexificação das relações de poder na sociedade civil, elevando a sociedade civil à dimensão superestrutural. Essa análise gramsciana origina o conceito de Estado ampliado (sociedade civil+sociedade política). Nesse contexto, o Estado, como superestrutura político-ideológica tem assumido o papel de educador da sociabilidade necessária à manutenção da sociedade de classes, ou seja, educação para o consenso em torno do projeto burguês de sociabilidade. Para a melhor compreensão do conceito pedagogia política, ver obra de Neves (2005), sendo cunhado como pedagogia da hegemonia.

${ }^{4}$ Esse programa foi desenvolvido a partir de 1995 e implementado em 1996, sendo substituído em 2003 pelo PNQ, no Governo Lula da Silva.
} 


\section{Trabalhonecessário}

Issn: 1808 - 799X

ano 11, no $16-2013$

dos partidários ${ }^{5}$ da Terceira Via, para verificar a correspondência aos pressupostos, princípios e diretrizes que compõem a atual configuração da política pública de trabalho, qualificação e geração de renda. Para alcançar esse objetivo, fizemos a análise do PLANFOR e do PNQ, como principais mecanismos da política pública de trabalho, qualificação e geração de emprego e renda. Em meio a essa síntese, identificamos os aspectos da atual pedagogia política nos documentos do PLANFOR e do PNQ, evidenciando seu potencial mediador do conflito de classes.

\section{A Pedagogia Política do Planfor e do Pnq}

Com base no conceito gramsciano de hegemonia, a manutenção da sociabilidade burguesa depende de uma combinação de instrumentos de coerção e persuasão. Nesse sentido, a sociabilidade burguesa consiste em um conformismo social, ou seja, uma forma de ser, pensar e agir adequada à dinâmica da valorização do capital. Esse conformismo consiste em uma forma de consciência coletiva que deve perpassar a totalidade da vida social, em graus diferenciados, porém mantendo um nível de apreensão coletiva que conserve as relações de dominação de classe e a dinâmica de valorização do capital. Assim, a reformulação da sociabilidade ou conformismo social decorre das mudanças na configuração da luta de classes, com modificações na estrutura e na

\footnotetext{
${ }^{5}$ Compreendemos como teóricos e partidários da Terceira Via, intelectuais como: Anthony Giddens, sistematizado em seu livro "A Terceira Via: reflexões sobre o impasse político atual e o futuro da social-democracia"; Carl Erick Sveiby, evidenciado em seu livro "A Nova Riqueza das Organizações"; Simon Schwartzman e Cristián, principalmente no livro "Políticas Educacionais e Coesão social: uma agenda latino-americana"; Pedro Paulo Carbone et all, em "Gestão por competências: e gestão do conhecimento".
} 


\section{Trabalhonecessário}

Issn: 1808 - 799X

ano 11, no $16-2013$

superestrutura da sociedade, como um processo dialético entre essas esferas sociais.

Como expressão da sociabilidade burguesa, o conceito de cidadania abstrata ganha contornos e significados de acordo com o avanço das forças produtivas e da modificação na dinâmica da organização do trabalho e da produção, além da complexificação das relações de poder no Estado. Dessa forma, o Estado com sua base de classe, como superestrutura político-ideológica de manutenção da sociedade de classes tem assumido o papel de educador da sociabilidade necessária à continuidade do metabolismo social do capital. Com esse objetivo os mecanismos de mediação do conflito de classes ou a pedagogia política acionada pelo Estado, com ações na sociedade civil e na sociedade política, tem a função de renovar a "cultura cidadã", conformando o conjunto da população à atual dinâmica do capitalismo monopolista.

A atual pedagogia política tem como objetivo principal a modificação do padrão de sociabilidade forjado pelo modelo de desenvolvimento de tipo taylorista/fordista, com regulação social de tipo keynesiano, para dar lugar a um novo padrão de sociabilidade forjado pelo modelo de desenvolvimento de tipo flexível, de produção enxuta, com regulação social de tipo neoliberal mediatizado pela Terceira Via, mais adequado às exigências de produtividade e competitividade de um mercado globalizado.

Nesse contexto, o reformismo como essência da socialdemocracia e sua principal função no processo histórico têm direcionado o desenvolvimento de um arcabouço teórico/metodológico voltado para o rebaixamento da consciência político-ideológica da classe trabalhadora e conformação ao projeto de sociabilidade burguês. Com novos contornos e significados, a Terceira Via expressa a essência socialdemocrata de ajustar a dinâmica social ao processo de valorização do capital. Assim, ao assumir o protagonismo social a 


\section{Trabalhonecessário}

Issn: 1808 - 799X

ano 11, no $16-2013$

socialdemocracia refina seu arcabouço teórico/metodológico, materializando uma nova interpretação do projeto neoliberal com a aparência de um capitalismo "mais humanizado". Nesse sentido, a principal preocupação da Terceira Via é com o restabelecimento da coesão social, ou seja, a construção de um novo bloco histórico, um novo equilíbrio entre estrutura e superestrutura necessário à manutenção das relações de dominação de classe e à dinâmica de valorização do capital.

A propósito, a preocupação com a coesão social constitui o principal direcionamento da política pública de trabalho, qualificação e geração de emprego e renda. É possível visualizar essa preocupação como princípio estruturante do PLANFOR e de seu sucessor, o PNQ. Essa preocupação pode ser percebida nos objetivos, nas metas, na destinação dos recursos, na definição do público alvo, na relação estabelecida entre Estado e sociedade civil. Adiante, faremos uma análise desses pontos principais.

Nos objetivos estabelecidos pelo PLANFOR, evidenciamos a preocupação com o combate à pobreza e à desigualdade social, a redução do desemprego e do subemprego. A mesma preocupação encontra-se na meta de qualificação de 20\% da População Economicamente Ativa (PEA), com foco prioritário para grupos vulneráveis, destinando $80 \%$ dos recursos para essa faixa da população. Além disso, esse Programa busca integração com outros programas e projetos sociais destinados à faixa da população mais afetada pelo processo de reestruturação da produção (BRASIL, 2001, p. 6), como podemos perceber nessa afirmação:

Ao mesmo tempo, o PLANFOR tem compromisso permanente de atender demandas de qualificação profissional de outros programas e projetos sociais públicos, notadamente aqueles que beneficiam populações mais pobres, sujeitas à exclusão, à discriminação, à violência e risco social (BRASIL, 2001, p. 6). 


\section{Trabalhonecessário}

Issn: 1808 - 799X

ano 11, no $16-2013$

Esses programas e projetos estão compreendidos nas áreas de direitos humanos, segurança pública, assistência social, gênero e raça, jovens, desenvolvimento sustentável, reestruturação produtiva (BRASIL, 2001, p. 6).

Para a edificação de um novo bloco histórico, o projeto neoliberal mediatizado pelas proposições da Terceira Via tem como objetivo a conformação de uma "nova cultura cidadã", mais adequada ao contexto de mundialização do capital. Essa "nova cultura cidadã" deve estar fundamentada no individualismo como valor moral radical, no empreendedorismo, no protagonismo social e na competitividade. Dessa forma, tanto o indivíduo quanto os organismos coletivos devem apreender um padrão predominante de ser, pensar e agir voltado para uma renovada forma de aceitação do modo de produção capitalista como único horizonte. A principal característica do "novo cidadão" é a aceitação das modificações na ordem competitiva como naturais, bem como suas mazelas como infortúnios e perturbações incidentais, isto é, acontecimentos casuais, fortuitos, imprevistos que, apesar de supostamente não fazerem parte do modelo de desenvolvimento proposto - ou até mesmo serem opostos a ele em alguns casos -, ocorrem de modo inevitável e exigem adaptabilidade. Além da flexibilidade necessária para adaptação às mudanças e mazelas da ordem social capitalista, esse "novo cidadão" precisa ser proativo, colaborador, voluntário, ou seja, ser um sujeito ativo na construção do projeto de sociabilidade de novo tipo, mais flexível, tolerante e crente na possibilidade de harmonização dos interesses distintos que perpassam a sociedade civil.

Com base nos textos de Neves (2005), Lima e Martins (2005) e Lima (2008), podemos afirmar que, em linhas gerais, o projeto neoliberal mediatizado pela Terceira Via está estruturado em um arcabouço teórico voltado para: a) a naturalização do modo de produção capitalista, como única forma de sociabilidade possível, legitimando a manutenção das relações sociais fundadas

TrabalhoNecessário - www.uff.br/trabalhonecessario; Ano 11, № 16/2013. 


\section{Trabalhonecessário}

Issn: 1808 - 799X

ano 11, no $16-2013$

na dominação de classe; b) essa naturalização está assentada no ataque frontal ao projeto socialista e rejeição da política de classes; c) o desenvolvimento de uma política de conciliação de classes fundamentada no diálogo social como única forma de negociação entre capital e trabalho, ou seja, a promoção da concertação social em outro formato, um novo pacto social condicionando as ações políticas sociais à dinâmica do mercado; d) a reconfiguração da relação entre Estado e sociedade civil, possibilitando a modificação do padrão de sociabilidade expresso no modelo de Estado de Bem-Estar Social e promovendo a inserção social em formas distintas desse modo de regulação social. A partir desses objetivos principais, os teóricos da Terceira Via fundamentam seu projeto político-ideológico com base em três pressupostos: 1) o surgimento de uma nova ordem pós-tradicional; 2) o fenômeno da "globalização intensificadora" 3) a "expansão da reflexividade social".

A noção da atual configuração social como um fenômeno caracterizado pelo surgimento de uma "nova ordem pós-tradicional" dá suporte políticoideológico à naturalização do capitalismo e à legitimação da sua atual configuração de ampliação da exclusão social e desemprego estrutural. Essa argumentação é construída com referência em análises deslocadas da realidade, tomando a dinâmica social capitalista e seus efeitos degradantes como fenômenos naturais e inevitáveis. A argumentação está pautada em uma concepção abstrata de homem. Assim, a configuração atual da luta de classes se torna um mundo de incertezas e perturbações sem o direcionamento do homem, propagando-se que não cabe ao homem a condução do processo histórico, pois ele segue por si, naturalmente. A partir dessas concepções sem historicidade, sem fundamentação na realidade, a Terceira Via, expressão da socialdemocracia na contemporaneidade, afirma a ocorrência de uma crise da tradição fundamentalista, de toda a tradição conservadora, gerando uma "tradição 


\section{Trabalhonecessário}

Issn: 1808 - 799X

ano 11, no $16-2013$

reflexiva" fundamentada na lógica de conciliação de classes, no modelo dialógico e reflexivo.

Outro fenômeno identificado e analisado de forma cíclica pela Terceira Via consiste na "globalização intensificadora". Com essa noção, a argumentação teórica é construída desconsiderando a mundialização do capital, como um momento da configuração atual da luta de classes. Com a negação das condições objetivas e subjetivas da realidade social os partidários da Terceira Via concebem a mundialização do capital como uma "globalização intensificadora", um fenômeno de predominância cultural desencadeado pelo desenvolvimento e disseminação em nível mundial das tecnologias de informação, desencadeando uma intensa comunicação em nível global. Dessa forma, a tecnologia por ela mesma tem provocado uma intensa modificação cultural, com mudança de hábitos, costumes estilos de vida, na direção de constituição de hábitos e valores universalistas. Essas mudanças na visão da Terceira Via tem edificado uma percepção das relações sociais no mundo globalizado como uma espécie de "comunidade global", uma "aldeia global" interligada. Assim, a visão harmoniosa de sociedade ideologizada pela Terceira Via desconsidera também os diversos mecanismos de controle do mercado, os mecanismos de controle migratórios e imigratórios, além da configuração atual do capitalismo monopolista que só precisa de uma parte dos trabalhadores inserida no processo produtivo, relegando uma significativa parte da população mundial à exclusão da esfera produtiva.

Com base nessa noção da "globalização intensificadora", os teóricos da Terceira Via fundamentam-se no pressuposto da "expansão da reflexividade social". Com uma análise cíclica do uso da tecnologia da informação no meio social, decorre uma percepção da disseminação e acesso à informação sem considerar os diversos mecanismos de controle de acesso à informação e ao conhecimento. Além disso, essa concepção compreende informação como 


\section{Trabalhonecessário}

Issn: 1808 - 799X

ano 11, no $16-2013$

conhecimento. Nesse sentido, o atual nível de fluxo de informações geraria um mundo de pessoas mais inteligentes e mais responsáveis socialmente (engajadas na conservação da ordem social burguesa). Nessa análise, o aumento do uso da informação na economia estaria forjando uma nova ordem social, uma sociedade sem classes, uma sociedade da informação, onde a categoria "trabalho" perde sua centralidade na análise do fenômeno social ${ }^{6}$. Essa nova ordem social composta por cidadãos "mais informados" e "educados" exigiria nova postura social pró-ativa, nova postura política, postura socialmente responsável, fundamentando a necessidade da construção de uma sociedade civil ativa. Essa "nova sociedade civil ativa" exige a mudança na concepção de indivíduo como sujeito de direitos para a concepção de atores sociais prestadores de serviços, atores responsáveis socialmente pela construção de uma sociedade concebida como espaço de ajuda mútua, em forma de um amplo mutirão, condicionada a dinâmica de valorização do capital.

Nesse contexto, os pressupostos político-ideológicos do projeto neoliberal mediatizado pela Terceira Via dão suporte à modificação no papel do Estado e em sua relação com a sociedade civil. Essas mudanças são apresentadas como necessidade decorrente dos três fenômenos evidenciados pela Terceira Via, tais como: o surgimento de uma nova ordem pós-tradicional, a globalização intensificadora e a expansão da reflexividade social.

São esses os pressupostos que direcionam toda a construção do PLANFOR e do PNQ. Como podemos verificar tanto nos objetivos do PLANFOR como nos do $P N Q$, a qualificação profissional assume a função estratégica de construção de uma sociedade sustentável, com foco no desenvolvimento com equidade social. Já nos objetivos desses programas podemos visualizar a necessidade da

\footnotetext{
${ }^{6}$ A propósito, categoria trabalho nessa formulação dos teóricos da sociedade da informação é equivalente a trabalho assalariado, então, não compreende o sentido ontológico do trabalho.
} 


\section{Trabalhonecessário}

Issn: 1808 - 799X

ano 11, no $16-2013$

construção de uma sociedade civil ativa, comprometida com um modelo de desenvolvimento voltado para a elevação da produtividade e da competitividade do setor produtivo. Como podemos perceber no seguinte objetivo estabelecido pelo PLANFOR: “[...] o PLANFOR trata de promover a qualificação profissional como direito do trabalhador e componente básico do desenvolvimento sustentado, com equidade social" (BRASIL, 2001, p. 3). Esse fragmento também indica a necessidade de qualificação social para a construção da sociedade civil ativa, pois a qualificação como direito do trabalhador estabelece a necessidade de qualificar o trabalhador para a promoção de um mundo sustentável, ou seja, a construção do consenso, do consentimento ativo para edificar a sociedade civil ativa, engajada no projeto empresarial de elevação da produtividade, proporcionando a competitividade necessária à atual conjuntura de acirramento da competição mundial.

A sociedade civil ativa, conformada às leis de mercado, à dinâmica de valorização do capital, assume a forma de uma sociedade de ajuda mútua, ou seja, uma sociedade de bem-estar social promovido pelos próprios indivíduos, sem o Estado. Podemos compreender esse movimento com a disseminação, em nível mundial, do conceito de sustentabilidade, o qual expressa uma concepção de sociedade organizada por interesses específicos e forte estímulo ao individualismo como valor moral radical, para a constituição da sociedade como espaço de ajuda mútua.

Visualizamos tanto no PLANFOR quanto no PNQ, a perspectiva da construção de uma sociedade sustentável embasada no apelo ambiental, no desenvolvimento com respeito ao meio ambiente, ou seja, desenvolvimento com responsabilidade social individual e coletivo. Porém, essa perspectiva está mais estruturada no $P N Q$, como uma das diretrizes principais para a formulação do Plano Plurianual (PPA), conforme se pode visualizar a seguir:

TrabalhoNecessário - www.uff.br/trabalhonecessario; Ano 11, № 16/2013. 


\title{
Trabalhonecessário
}

Issn: 1808 - 799X

ano 11, no $16-2013$

\begin{abstract}
O PPA articula-se em torno de três mega-objetivos: a)inclusão social e redução das desigualdades sociais; b) crescimento com geração de trabalho, emprego e renda, ambientalmente sustentável e redutor das desigualdades regionais; e c) promoção e expansão da cidadania e fortalecimento da democracia (BRASIL, 2003, p. 17).
\end{abstract}

O apelo ambiental legitima a construção de uma sociedade sustentável ou um mundo sustentável, um mundo comprometido com metabolismo social do capital. Para a construção dessa sociedade sustentável, o estímulo à responsabilidade social individual e coletiva funciona como pressuposto político ideológico de engajamento das ações individuais e coletivas em prol da dinâmica do capital. Ou seja, a disseminação da necessidade de desenvolvimento da responsabilidade social se torna a construção do consenso e do consentimento ativo. Assim, responsabilidade social se torna o consentimento ativo ao projeto de sociabilidade burguês.

Tanto no nível individual como no coletivo a responsabilidade social expressa a necessidade de renovação da "cultura cidadã", ganhando novos contornos e definições. No nível de organismos coletivos, essa "cultura cidadã" é expressa pelas definições de sindicato cidadão, empresa cidadã e/ou empresa socialmente responsável etc. No nível individual assume formas de estímulos ao protagonismo social, ao empreendedorismo, fundamentados no individualismo como valor moral radical e no desenvolvimento da competitividade no mercado de trabalho, na forma de capital humano adquirido pela formação e qualificação profissional. Essas concepções político ideológicas, que dão forma à renovação da "cultura cidadã", têm como objetivo mais geral a construção de uma sociedade sustentável e engajada na dinâmica de valorização do capital.

A análise do conceito de equidade se torna importante para entender os propósitos formativos dessa política de qualificação profissional. A busca da equidade social é, na realidade, a busca de condições básicas de sobrevivência na atual dinâmica excludente do mercado. Equidade, por sua vez, é utilizada para

TrabalhoNecessário - www.uff.br/trabalhonecessario; Ano 11, № 16/2013. 


\section{Trabalhonecessário}

Issn: 1808 - 799X

ano 11, no $16-2013$

legitimar a busca ilusória de maior "justiça social" em convivência com crescente desigualdade econômica e social. Dessa forma, o conceito de equidade social é utilizado para naturalizar a ampliação do desemprego e da precariedade das condições de trabalho.

Podemos verificar os aspectos da ideologia da globalização, com a naturalização das mazelas da dinâmica excludente do mercado, verificando a meta estabelecida pelo PLANFOR. Assim, podemos identificar alguns aspectos dos pressupostos estabelecidos pelos partidários da Terceira Via. As mudanças atuais, ou seja, um "mundo de perturbações e incertezas" provocadas pelo processo de reestruturação produtiva é tomado como natural. Dessa forma, a qualificação profissional (criadora de postos de trabalho) assume a função de proporcionar uma chance, uma possibilidade de atualização profissional para a inserção nesse mercado em constante mutação.

Em linhas gerais, essa pedagogia política pautada na reinterpretação do projeto neoliberal pela Terceira Via assume a forma de um movimento amplo de repolitização da política, com três movimentos principais: 1) o rebaixamento do conjunto da população ao nível mais elementar da consciência política, estimulando um tipo de participação política pautada em interesses individualizados, uma participação sem poder de decisão real, condicionada à dinâmica de valorização do capital; 2) ofensiva aos organismos de representação da classe trabalhadora, com seu desmantelamento e/ou refuncionalização, modificando a dinâmica de ação desses organismos voltada para a ampliação de direitos sociais. 3) estímulo estatal ao desenvolvimento e expansão de organismos de interesses específicos e focalizados, não diretamente envolvidos com a regulação do trabalho (NEVES, 2005, p. 33-39).

Em relação à ofensiva aos organismos de representação da classe trabalhadora, o desmantelamento e a refuncionalização têm como objetivo 


\section{Trabalhonecessário}

Issn: 1808 - 799X

ano 11, no $16-2013$

neutralizar qualquer tentativa de construção de contra-hegemonia, de um novo projeto de sociabilidade. Dessa forma, essa ofensiva se configura no engajamento da classe trabalhadora na construção da grande política da conservação, com o rebaixamento do nível de consciência política e estímulo à pequena política pautada em interesses individualizados (NEVES, 2005, p. 33-39).

Os organismos de representação de interesses específicos surgiram no Pós-ll Guerra, como organismos privados de representação de interesses tangenciais aos de classe, ou seja, interesses extra-econômicos, tomando a forma de organizações não-governamentais (ONG), formalmente definidas como organizações privadas de interesse público. Assim, as políticas do Estado para a expansão desses organismos, na configuração atual do capitalismo, funcionam como estratégia de diluição do conflito de classes, com a descaracterização das relações de dominação de classe, camuflando as relações de exploração e expropriação e estimulando o individualismo como valor moral radical. Além disso, esse processo de reconfiguração do papel do Estado pode ser evidenciado na dinâmica de privatização das políticas sociais, abrindo novos campos para a acumulação de capital, como expressão da transformação do Estado de produtor de bens e serviços em coordenador de iniciativas no âmbito da sociedade civil (NeVEs, 2005, p. 33-39).

Podemos ver como estão estruturados esses três movimentos da atual pedagogia política, analisando o seguinte fragmento do PNQ (BRASIL, 2003, p. 17):

A ampliação da participação da sociedade na construção do PPA é um dos mais importantes aspectos que o caracterizam e diferenciam de procedimentos anteriores. $\mathrm{O}$ caráter participativo significa um enriquecimento permanente do planejamento e da gestão das Políticas Públicas e marca uma nova relação entre Estado e Sociedade. De um lado, consolida um Estado eficiente, ágil e controlado pelos cidadãos, um Estado adaptado às exigências do novo ciclo de desenvolvimento. De outro lado, reforça a sociedade na perspectiva da cidadania ativa, de um novo contrato social, do fortalecimento da

TrabalhoNecessário - www.uff.br/trabalhonecessario; Ano 11, № 16/2013. 


\section{Trabalhonecessário}

Issn: 1808 - 799X

ano 11, no $16-2013$

democracia em todas as suas dimensões, da radicalização do processo democrático como um grande movimento cultural.

Nesse fragmento, percebemos os objetivos de conformação de uma cidadania ativa como forma de construção de um novo pacto social condicionado aos limites da democracia restrita burguesa. Identificamos também a necessidade de reformulação da relação entre Estado e sociedade civil. Nesse sentido, nossa análise do PLANFOR e de seu sucessor, o PNQ, tem demonstrado que a política de qualificação profissional está estruturada como mecanismo de mediação do conflito de classes, voltada para o desmonte da sociabilidade do tipo de bemestar social e engajada na conformação ao atual padrão de sociabilidade neoliberal, mais adequado à dinâmica de valorização do capital.

Como podemos perceber na ofensiva burguesa, a subsunção real do trabalho ao capital acionada no nível estrutural, expressa no regime de acumulação flexível, assume contornos, no nível superestrutural, de subsunção real do conjunto da população mundial ao projeto neoliberal verificada na necessidade de construção do consentimento ativo decorrente da complexificação e sofisticação dos mecanismos de mediação do conflito de classes.

\section{Considerações Finais}

A título de considerações finais, observamos que, diante do crescimento da contestação social e ameaça à hegemonia burguesa, em meados dos anos 1990, a reconfiguração do projeto neoliberal mediatizado pela Terceira Via é apresentado como suposta alternativa a este projeto. Com o objetivo de aprofundar as reformas neoliberais e eliminar os componentes do Estado de BemEstar-Social, os partidários da socialdemocracia ou Terceira Via sistematizam seu aparato político-ideológico em teses deslocadas da realidade, apresentando a

TrabalhoNecessário - www.uff.br/trabalhonecessario; Ano 11, № 16/2013. 


\section{Trabalhonecessário}

Issn: 1808 - 799X

ano 11, no $16-2013$

ordem social capitalista como única alternativa viável para a humanidade. Esse conteúdo político-ideológico tem como objetivo legitimar as mudanças no nível estrutural, por meio de uma pedagogia capaz de conformar ética e moralmente a sociedade civil aos princípios das leis de mercado.

Nesse contexto de reordenamento da política e da economia, o diálogo social se torna uma das principais diretrizes do projeto de sociabilidade burguês, consistindo em ampla estratégia de reordenamento da política, em nível mundial, fundamentada na possibilidade de conciliação de interesses antagônicos entre capital e trabalho.

Nesse sentido, o diálogo social como uma das principais diretrizes do projeto neoliberal mediatizado pela Terceira Via está voltado para o desmonte do Estado de Bem-Estar Social e a conformação da sociedade civil nos limites das leis de mercado. Ao mesmo tempo em que essa engenharia institucional está voltada para a mediação do conflito de classes, promovendo a harmonização ou coesão social, ela abre espaços de participação limitada na estrutura de controle do Estado. Nesse sentido, essa estratégia se constitui na tentativa de resolução provisória da contradição entre a socialização do poder político e a apropriação privada do poder.

Com base nas diretrizes do projeto neoliberal mediatizado pela Terceira Via, em meados dos anos 1990, o Estado brasileiro aprofunda a reconfiguração de sua relação com a sociedade civil e dos mecanismos de mediação do conflito de classes. Com esse objetivo, o Governo FHC intensifica as mudanças desencadeadas pela hegemonia do projeto neoliberal, mais evidente no início dos anos 1990. Desse processo decorre ampla reforma do sistema educacional brasileiro e a criação de uma complexa engenharia institucional para 0 desenvolvimento da política pública de trabalho, qualificação e geração de emprego e renda. Nesse sentido, as políticas educacionais se tornam 


\section{Trabalhonecessário}

Issn: 1808 - 799X

ano 11, no $16-2013$

mecanismos estratégicos de conformação de um trabalhador de novo tipo, mais adaptado ao funcionamento do aparelho econômico e condicionado às leis de mercado.

Nesse contexto, a política pública de trabalho e renda é articulada à política de formação e qualificação profissional, estruturada com 0 arcabouço político/metodológico do projeto neoliberal mediatizado pela Terceira Via. A disseminação dessa nova "cultura" articulada à ideologia da qualificação profissional proporciona o aparato político-ideológico voltado para a construção da sociedade civil ativa e a formação de um novo bloco histórico. Essa disseminação é realizada em meio ao fomento da participação política de representações da classe trabalhadora. Nesse sentido, o fomento à participação política se constitui no processo de socialização política, porém uma socialização limitada aos pressupostos da engenharia institucional e condicionada às regras estabelecidas pelo órgão normalizador. Assim, o fomento à participação política da classe trabalhadora dentro dos limites da dinâmica da ordem social constitui elemento importante no reordenamento das relações de poder, para a manutenção da sociedade de classes. 


\section{Trabalhonecessário}

Issn: $1808-799 X$

ano $11, \mathrm{n}-16-2013$

\section{Referências}

ALVES, Giovanni. O novo (e precário) mundo do trabalho: reestruturação produtiva e crise do sindicalismo. São Paulo: Boitempo, 2005.

ANTUNES, Ricardo. Os sentidos do trabalho: ensaio sobre a afirmação e a negação do trabalho. São Paulo: Boitempo, 2005.

BRASIL/MTE. Plano Nacional de Qualificação - PNQ, 2003-2007. Brasília: MTE, SPPE, 2003.

BRASIL/MTE/SPPE. Guia do PLANFor 2001. Brasília: MTE/SPPE, junho/2001.

CHESNAIS, François. A mundialização do capital. Traduzido por Silvana Finzi Foá. São Paulo: Xamã, 1996.

GRAMSCI, Antônio. Maquiavel, a política e o Estado moderno. Traduzido por Luiz Mário Gazzaneo. 7.ed. Rio de Janeiro: Civilização Brasileira, 1989.

LIMA, Kátia Regina de Souza; MARTINS, André Silva. Pressupostos, Princípios e Estratégias. In: NEVES, Lúcia Maria Wanderley (Org.). A nova pedagogia da hegemonia: estratégias do capital para educar o consenso. São Paulo: Xamã, 2005. p. 43-67.

LIMA, Kátia. Novas configurações da luta de classes e refundação do projeto burguês de sociabilidade. Trabalho Necessário, Rio de Janeiro, v.6, n.6, 2008.

MÉSZÁROS, István. A ordem do capital no metabolismo social da reprodução. Ensaios Ad Hominem - Revista de Filosofia, Política e Ciência da história. N.1, Tomo I, p. 83-124, 1999.

NEVES, Lúcia Maria Wanderley (Org.). A nova pedagogia da hegemonia: estratégias do capital para educar o consenso. São Paulo: Xamã, 2005.

SOUZA, José dos Santos. A "nova" cultura do trabalho e seus mecanismos de obtenção do consentimento operário: os fundamentos da nova pedagogia do capital. In: BATISTA, Roberto Leme; ARAÚJO, Renan (Org.). Desafios do trabalho: Capital e luta de classes no século XXI. Maringá (PR): Praxis, 2003. p. 173-200.

Data de recebimento: 13/03/2013 Data de aprovação: 05/04/2013 